Distinguishing Post-Traumatic Growth from Psychological Adjustment among Rwandan Genocide Survivors

Laura E. R. Blackie

Department of French and Francophone Studies, University of Nottingham, UK Eranda Jayawickreme

Department of Psychology, Wake Forest University, USA

\author{
Nicki Hitchcott \\ Department of French and Francophone Studies, University of Nottingham, UK \\ Stephen Joseph \\ School of Education, University of Nottingham, UK
}

Word count: 6,136

Acknowledgments: This research was supported by a grant AH/M004155/1 awarded by the Arts and Humanities Research Council. The research was conducted in collaboration with the Aegis Trust who granted Dr Nicki Hitchcott and her team access to interviews stored in the Genocide Archive of Rwanda. The Aegis Trust is a Nottinghamshire-based NGO that oversees and manages the work of the Genocide Archive of Rwanda. The interviews with genocide survivors quoted in this chapter were conducted by staff members at the Genocide Archive of Rwanda. All survivors signed a consent form and gave permission for their interview to be stored in the national archive. The survivors were given the choice as to whether to allow their interview to be shared with individuals outside of the archive team including researchers, educators and policymakers. The lead author worked alongside staff at the archive to select a corpus of interviews in 
which consent had been granted for use in research. The opinions expressed in this publication are those of the authors and do not necessarily reflect the views of either the Genocide Archive Rwanda or the Aegis Trust. Correspondence concerning this chapter should be addressed to Laura E. R. Blackie, Department of French and Francophone Studies, University of Nottingham, University Park, Nottingham, NG7 2RD. Email: laura.blackie@,nottingham.ac.uk 
"Being stripped of your life is not easy to live with. Although life is hard, we must continue to live to prove to those who tried to take it away that they are not life-givers. And things did not go as they planned. Some people died, but there are always survivors."

G-MM, Rwandan Genocide Survivor

"After surviving the genocide, there is a principle I have tried to base my life on that helped me move forward. It says the best way to get revenge is to succeed."

GM, Rwandan Genocide Survivor

"If we survived the way we did, our task is to bless the rest of the country. Our task is to tell everyone that there is no profit in killing anyone. We are left to witness that, those who killed gained nothing and we must help them to rebuild their conscience and repent. I realised that the duty of survivors is very far-reaching."

LU, Rwandan Genocide Survivor

The above quotations are extracts taken from the oral testimonies of survivors of the 1994 Genocide against the Tutsi in Rwanda. These survivors chose to share their story and record their history with the Genocide Archive Rwanda. Their testimonies function not only to document Rwanda's past and preserve the memory of the genocide's many victims, but also as educational tools to prevent genocide and foster peace and reconciliation. It is difficult to assess or comprehend the impact of the genocide in which nearly $75 \%$ of the Tutsi population were brutally murdered by their fellow and predominantly Hutu neighbours in just 100 days (Clark, 2010, p.12). The aid organisation Survivors Fund (SURF) reports that the genocide resulted in the deaths of 800,000 to $1,000,000$ people, leaving 50,000 women widowed, 75,000 children orphaned, and approximately $67 \%$ of the 250,000 to 500,000 women who had been raped during the genocide living with HIV (Survivors Fund, n.d.). The genocide was deeply traumatising and, 
as can be seen from the extracts above, survivors were faced with the seemingly impossible task of rebuilding their lives in the wake of such tragedy.

The negative impact of adversity has long been studied (Seligman \& Csikszentmihalyi, 2000), but more recently psychologists have found that individuals struggling with difficult and often traumatic experiences will sometimes identify ways in which they have drawn strength from their experience (Tedeschi \& Calhoun, 2004). Indeed, the survivors' comments provide anecdotal evidence in support of this phenomenon, most commonly referred to as posttraumatic growth (Tedeschi, Park, \& Calhoun, 1998). However, controversy over this concept exists, particularly surrounding the extent to which retrospective self-reports of growth reflect genuine changes to an individual's personality, rather than an illusory belief used to restore a sense of control and optimism about the future (Jayawickreme \& Blackie, 2014, p.319). A central debate in this literature has therefore focused on whether post-traumatic growth is really more than psychological adjustment to post-trauma reality. In this chapter, we draw upon testimonial data from a sample of survivors of the 1994 genocide in Rwanda to evaluate this issue. This population provides a relevant context with which to assess this question, as the severity and collective nature of the genocide made adjustment to post-genocide life a tragic necessity.

\section{What is Post-Traumatic Growth?}

Post-traumatic growth is broadly defined as positive psychological change experienced as a result of struggle with highly challenging life circumstances (Tedeschi \& Calhoun, 2004). It is measured in terms of increases in five domains: relationships; appreciation of life; new possibilities; spirituality; and personal strength (Tedeschi \& Calhoun, 1996). Although these domains were originally developed through clinical interviews with US citizens who had suffered a range of different crises, from bereavement to physical disability, the relevance of these domains has been shown to apply cross-culturally and to survivors of extreme trauma, including traumatised Somali refugees (Kroo \& Nagy, 2011), refugees from the civil war in Yugoslavia 
(Powell, Rosner, Butollo, Tedeschi, \& Calhoun, 2003), Holocaust survivors (Lurie-Beck, Liossis, \& Gow, 2008) and former political prisoners in Palestine (Salo, Punamäki, Qouta, \& Sarraj, 2008). Some Rwandan genocide survivors have reported post-traumatic growth. Arnold (2011) found that higher post-traumatic growth was reported by individuals with a strong sense of optimism and perceived control and greater exposure to genocide-related traumas. Posttraumatic growth has also been identified in qualitative analyses of survivor testimonies in the form of drives for autonomy and communion among female survivors (Williamson, 2014), and a shared sense of national identity among male survivors (Williamson, 2016).

Some theorists have argued that post-traumatic growth occurs following a cognitive restructuring process referred to as accommodation (Joseph \& Linley, 2005). The starting point for this theory is the assumption that a traumatic experience has the potential to challenge severely (or even shatter) an individual's prior beliefs and assumptions about the world, leading them to question whether they live in a safe, benevolent, and predictable world (Janoff-Bulman, 2010; Tedeschi et al., 1998). This process is extremely distressing, and for post-traumatic growth to occur, an individual must therefore eventually disengage from prior beliefs and goals that no longer make sense in their current situation. It is this move to a more deliberative and effortful processing of the event that may eventually enable individuals to search for meaning in their experience, and to rebuild their identities in a manner that incorporates these lessons (Tedeschi \& Calhoun, 2004, pp.7-11). Joseph and Linley's (2005) model goes a step further, claiming that the lessons can be positive (e.g. life is short and should be cherished) or negative (e.g. the world is unsafe and no-one can be trusted). The result of such cognitive processing can be either posttraumatic growth or hopelessness and depression.

What is the Relationship between Post-Traumatic Growth and Adjustment?

Importantly, the positive changes that individuals identify through the process of posttraumatic growth are suggested to be more than just fleeting silver linings. Post-traumatic growth 
is considered to result in genuine and transformative positive changes to individual identities, relationships and worldviews. According to Tedeschi \& Calhoun (2004, p.15): "The phenomenon is complex, and cannot easily be reduced to simply a coping mechanism, a cognitive distortion, psychological adjustment or well-being, or a host of apparently similar constructs." Given their strong stance, it is clear that without explicitly defining it as such, these authors are discussing the concept in terms of personality change (Jayawickreme \& Blackie, 2014, p.312). Personality psychology involves the study of individual differences in characteristic and enduring patterns of thoughts, feelings, and behaviours (Funder, 2001). In this context, a traumatic experience is the environmental trigger of changes to the individual's typical patterns of thinking, feeling and interacting.

However, the task of distinguishing post-traumatic growth from the related concept of adjustment is perhaps not so easy as Tedeschi \& Calhoun (2004) claim. This is because the definition of psychological adjustment is broad and has been measured in several different ways. Seaton (2009 pp. 796-801) writes that psychological adjustment has been defined both as an outcome denoting optimal mental health, and as a process of coping effectively with the demands of the environment along with the stress created by such demands. It has been assessed both as the absence of symptoms (e.g., anxiety, depression, functional impairment and PTSD) and with reference to indicators of well-being (e.g., self-esteem, satisfaction, positive affect). The inclusive nature of this concept has led some to distinguish between indicators of positive and negative adjustment. For example, a meta-analysis examining the relationship between religious coping and adjustment by Ano \& Vasconcelles (2005) defined positive adjustment in terms of acceptance, emotional well-being, hope, happiness, and post-traumatic growth; and negative adjustment in terms of anxiety, depression, PTSD, guilt, anger, hopelessness, and functional impairment. In other words, the term 'psychological adjustment' appears to be used quite broadly to refer to someone who is functioning well; hence some researchers have included posttraumatic growth under this larger umbrella. 
Given this, to what extent are post-traumatic growth and adjustment really distinct processes? We believe that the distinction drawn by Tedeschi \& Calhoun (2004) concerns the definition of adjustment as a process. In their model, post-traumatic growth is not merely conceived as a means to cope with the distress caused by a traumatic experience. Rather, some individuals are able to re-construct their identity in spite of pain and suffering. However, not all theorists agree with the idea that self-reports of post-traumatic growth are reflective of genuine personality change. Most notably, Taylor and Armor (1996) have referred to such changes as positive illusions, claiming that individuals will form positive beliefs as a means to manage distress and handle the negative impact of a stressful situation on their self-esteem, sense of control, and optimism about the future. Thus, reports of positive change are interpreted as a cognitive distortion that enables individuals to adjust and come to terms with stressful situations. While, other theorists have not taken such a strong stance, they have distinguished their own view by using another term. For example, Tomich and Helgeson (2004) have referred to it as 'benefit-finding', cautiously naming the phenomenon as it is typically measured: that is, in terms of an individual's perceptions of growth. In this account, researchers are more concerned with whether such beliefs predict improvements in mental and physical health than with whether the changes are genuine.

One reason why it is currently quite difficult to determine whether post-traumatic growth is indeed a matter of positive personality change is over-reliance on cross-sectional and retrospective measurement. Scales such as the Post-Traumatic Growth Inventory (Tedeschi \& Calhoun, 1996) are problematic, insofar as they ask individuals to estimate how much a traumatic event has changed their personality. Specifically, for every single item on this questionnaire, participants have to estimate their current standing in the domain, recall their previous standing, compare the two ratings, and then calculate how much of the identified change resulted from the trauma (Ford, Tennen, \& Albert, 2008, p.311). The problem with this type of questionnaire is that it cannot prevent memory and self-enhancement biases from colouring an individual's 
answers. It is impossible to determine whether Taylor and Armor (1996) are wrong, insofar as individuals might be unconsciously overestimating change as a means to feel better about their current situation. Moreover, reports of post-traumatic growth are fairly frequent, at least in Western populations, with individuals across a diverse range of stressful events endorsing at least one domain (Linley \& Joseph, 2004, pp.13-14). In the absence of rigorous methodological measurement, this could indicate that post-traumatic growth is simply a common coping response rather than genuine personality growth.

\section{Adjustment vs. Growth: Insights from Personality Psychology:}

Although issues with the measurement of post-traumatic growth have left some scholars sceptical about whether it actually captures positive personality change, the situation is perhaps not so bleak if we consider the broader literature on lifespan development. A growing body of cross-sectional and longitudinal studies have shown that personality traits do continue to change into adulthood (Lucas \& Donnellan, 2011; Mroczek \& Spiro, 2003; Helson, Jones, \& Kwan, 2002; Roberts, Caspi, \& Moffitt, 2001). These studies have discovered a normative trend for individuals to become increasingly confident, warm, responsible and calm as they get older (Roberts \& Mroczek, 2008, p.33). Furthermore, trait change occurs in response to significant experiences, including leaving university and gaining full-time work, retirement, marriage, birth of a first child, divorce/separation from a romantic partner, death of a parent, and bereavement after caring for a spouse with a terminal illness (Hoerger et al., 2014; Specht, Egloff, \& Schmukle, 2011; Löckenhoff, Terracciano, \& Costa, 2009; Roberts, Caspi, \& Moffitt, 2003; Roberts, Helson, \& Klohnen, 2002). While the personality traits measured in these studies do not necessarily capture post-traumatic growth, they do serve to demonstrate that personality change occurs after major life events. For Roberts and Mroczek (2008), however, such findings reflect a process of developmental adjustment. 
Not all psychologists believe that personality change is due to developmental adjustment. Of particular relevance, Staudinger \& Kunzmann (2005) have argued for two distinct types of positive personality change: adjustment and growth. Personality adjustment is defined as changes with adaptive and functional value for the individual and society: that is, the kind of normative trends described in the previous paragraph, which enables adaption to societal norms and social roles. The second type of personality change identified by these authors is believed to transcend societal value and represent an ideal end point of human development. Here, personality growth involves the development of character - including self-insight, integrity and self-transcendence eventually resulting in wisdom. According to Staudinger and Kunzmann (2005), these two types of positive personality change have unique developmental trajectories, as evidenced by agerelated changes in adjustment and the stability of growth in adulthood. Against evidence of changes in the big five personality traits in age-specific cohorts (Helson et al., 2002; Caspi \& Roberts, 2001), they review evidence showing no relationship between age and wisdom-related judgment (Kunzmann \& Baltes, 2003;Staudinger, 1999; Staudinger, Smith \& Baltes, 1992; Smith \& Baltes, 1990). On the basis of such evidence, they argue that personality growth is not a normative response to the increasing demands and changes of adulthood, but is more likely to be a rare occurrence.

Staudinger and Kunzmann (2005) have argued that a special constellation of personality and situational factors is necessary in order to promote personality growth, but their review is not specific on the factors involved. On the basis of existing literature on post-traumatic growth, we argue that confronting adversity might be one situational factor that facilitates personality growth above and beyond adjustment. Furthermore, the notion that post-traumatic growth may result in the development of character is not unexplored. Some scholars have claimed that the experience of post-traumatic growth results in greater wisdom (Tedeschi \& Calhoun, 2004, p. 12; Linley, 2003). Peterson, Park, Pole, D’Andrea, and Seligman (2008) found that individuals who had experienced a greater number of traumatic events in their lifetime also reported higher levels 
of the following character strengths: kindness; leadership; bravery; honesty; perseverance; appreciation of beauty; creativity; curiosity, learning; zest and religiousness. Related research on altruism born of suffering (Staub \& Vollhardt, 2008) has also shown that for some individuals the experience of violence and victimisation fosters compassion, empathy, and kindness. Finally, at least in contexts such as the genocide in Rwanda, forgiveness may also be an important and relevant character trait to consider. This response has been discussed with reference to the Holocaust; while it has been seen in some Holocaust survivors, it is not a common response (Burns, 2004, p.149).

\section{Adjustment vs. Growth: A Case Study with Rwandan Genocide Survivors:}

In an earlier article, some present authors have discussed whether the model put forward by Staudinger and Kunzmann (2005) could usefully illuminate work on post-traumatic growth (Jayawickreme \& Blackie, 2014, p.322). In this work, however, we attempt to evaluate this distinction by drawing upon a sample of testimonies from genocide survivors in Rwanda. In their model, Staudinger and Kunzmann (2005) claim that adjustment is personality trait change that has adaptive and functional value for the individual and society (i.e. strengthening of traits that promote social maturity enabling individuals to master new social roles). In the aftermath of the genocide in Rwanda, many survivors had little choice but to take on new roles and responsibilities. For example, widows had to undertake farming and agricultural duties normally undertaken by men, and orphaned children became heads of households with the responsibility of generating income and raising their siblings. The collective nature of the genocide meant that it not only destroyed the lives of individuals, but also the social fabric of Rwandan culture. We have therefore defined adjustment as a cognitive, emotional, or behavioural coping strategy that might allow survivors to manage the distress and any related difficulties in adjusting to new social roles/responsibilities/expectations for the future. 
Alternatively, and consistent with the Staudinger and Kunzmann (2005) model, we define personality growth - that is, post-traumatic growth - in terms of character traits and virtues that are conducive to human flourishing. This category of responses extends beyond managing the emotional distress triggered by the event to involve the development of positive qualities that are valuable in and of themselves (such as empathy, courage, and wisdom). Specifically, in the spirit of Park and Peterson (2009), we focus on the development of character traits and virtues that are both morally desirable and important indicators of positive human development. In this chapter, however, we make a further distinction between adjustment outcomes that function to enable survivors to manage the suffering inflicted by genocide, and growth outcomes that enable survivors to thrive (not just cope) with their new post-genocide existence.

The thematic analysis presented in this chapter is based on 32 oral testimonies retrieved from the Genocide Archive Rwanda, based in Kigali and managed by UK NGO, the Aegis Trust. Individuals gave their written consent and agreement for their testimony to be stored in the public archive and accessed by staff, educators, policy-makers and researchers. An archive staff member, also typically a survivor, conducted interviews in the individuals' native language: Kinyarwanda. Each interview was divided into sections: before, during, and after the genocide. The interviewer was careful to ask non-directive questions that did not elicit influenced responses. For example, a question asked in the post-genocide section was "How has your life been since the genocide?" which allowed the individual to direct the course of the topics discussed.

The interviews were collected during 2004-2011 when the archive received funding to record and translate a sample of 50 testimonies from both survivors and rescuers for the USC Shoah Foundation. Here, our analysis focuses on survivor testimonies, and we have selected only the testimonies for which the English translation was of sufficient quality to enable clear analysis. Our sample contains testimonies from 17 males and 15 females ranging in age at the time of the genocide from 9 to 48 years old. Using Jayawickreme, Jayawickreme, Goonasekera, and Foa's 
(2009) qualitative analysis of war-affected civilians in Sri Lanka as a guide, we used an opencoding method. Each testimony was analysed separately line-by-line. Tentative themes relevant to positive outcomes were identified in each testimony. Once this process had been repeated for all 32 testimonies, a thematic analysis was undertaken to identify master themes relevant to the aforementioned definitions of adjustment and growth. At this point, we should also note that survivors did report that the genocide had negatively impacted their life with issues ranging from anxiety, depression and alcoholism. Thus, although our analysis is focused on positive and adaptive responses to trauma, it does not imply that survivors are not still struggling or in pain.

Our analysis has identified three themes of adjustment: acceptance, hope and responsibility to live. Acceptance is characterised by recognition that the past cannot be changed. This theme is illustrated in the following extract:

"We have to accept what happened. It just happened, but we do not have to get stuck on that. We do not have to get stuck in a box. No, we need to realise that. I would say it is like the French saying, after failure life goes on".

This survivor then goes on to say, "We have to keep the memory of the victims alive, but we do not need to remain grieving. We have to move forward". We have classified this theme of acceptance as a form of adjustment, insofar as it enables survivors to disengage from their painful past and focus on rebuilding their futures.

Relatedly, the theme of hope is essential in enabling survivors to believe that it is possible to rebuild their lives. In this context, this is characterised by a belief that the Rwandan government is re-structuring society and educating youth in such a way as to ensure that genocide will never happen again. For example, this survivor says:

"Before, some Rwandans had a voice and others did not; but today everyone has a voice. We can speak without a problem. Today there is no segregation, like before. Ethnicity used to be written on identity cards and now it is not. The way I see the future of Rwanda, because of those things that are now disappearing, I think there will be some 
improvements. Our descendants will see the archive and ask themselves: why did it happen like this?”

Another survivor echoes this sentiment:

"I am very hopeful for the future. If I look back at what happened to us, I realise that things keep on changing little by little. They can't change all of a sudden, and of course some things are missing, but we have achieved a lot so far. I am very hopeful for the future."

Thus, survivors' hope for a better future is strongly dependent on feeling supported and protected by their government.

Our final theme of adjustment was related to the meaning that individuals attached to the survivor identity. The testimonies reveal that survivor identity often depends on a strong sense of duty to live well, which takes two related forms: being successful in life and avoiding coping with pain through negative behaviours such as intoxication and prostitution. One of the opening quotations of this chapter well illustrates the duty to be successful in life: the survivor explains that a successful life is the best form of revenge. Many survivors express this sentiment in their testimonies. For example, another remarks that, "when survivors live a bad life, it gives the enemy strength"; and another comments,

"The dead are gone and we will never see them again. We, the survivors, must be where they ought to be. Working and starting families. For those who can, having children, so the Tutsi they had wanted to exterminate live again."

While all survivors are aware of the pain caused by the genocide, their desire for a successful life helps them identify what are unacceptable ways of managing that distress. One survivor simply states:

"We have to live in harmony and seek the development of our country. The children who survived should be committed to their studies. Even though the genocide happened, life goes on. Don't be lazy, an alcoholic, a prostitute, or a bully. They wanted 
us to die, but we did not. Why should we be killed by those drugs or our carelessness, when we survived the machetes?"

Countless more examples of this theme occur in the testimonies. It is therefore clear that one adaptive way in which survivors have handled their new post-genocide life is to focus on living successful lives despite continuing pain and ongoing challenges.

Our analysis has identified three themes of growth: empathy, wisdom, and forgiveness. All such responses extend beyond adjustment, and represent positive qualities and virtues indicative of human flourishing. In line with the theory of altruism born of suffering (Staub \& Vollhardt, 2008), we observe that survivors understand and empathise with one another's situations. This helps promote a strong sense of commitment and social responsibility among individuals, strengthening in turn their identity as survivors. This theme is well illustrated by the following survivor:

"What I think should be done for survivors who face trauma is to get close to them in the beginning. We must deal with it in such a way that everyone should feel concerned about whether their neighbouring survivor is living a bad life. As a surviving orphan, going hungry during the day and sometimes going without food and shelter at night, I would think to myself, if my mother was here this wouldn't have happened. If my father was alive, this wouldn't have happened to me. This can be very distressing. I wish those whom I lost were here to help me. That is why I say, that everyone should be close and feel concerned about other people's problems."

More surprisingly, some survivors extend this empathetic concern to perpetrators of genocide. One survivor talking about the responsibility she feels to rebuild her country said: "That is when I started considering people the same and saw that even killers need help. They also need prayers to clean their hearts." Her ability to empathise and humanise the perpetrators appears to involve more than managing the pain of her own past. 
Likewise, our analysis reveals that survivors understand the importance of education in the prevention of violence. We classify this theme as expressive of wisdom, insofar as survivors recognise the necessity of taking social action to prevent Rwanda's youth from repeating history. One survivor explains:

'We don't want to teach them [Tutsi youth] to have bad hearts because of the injustice that we faced. When we tell them about the genocide, we have to tell them about the consequences, but show them that hatred is not the solution. We must instead show them the need to eliminate the ideology, so our youth don't have the same ideologies and in time want to seek revenge."

Another survivor talks about how this brother is supporting the child of a perpetrator to ensure that history is not repeated: "I can tell you that even my twin, took in the child of a person who killed our family. The sector leader helps him pay his school fees. A crime doesn't grow old, but the child is innocent and is not supposed to pay for what his father did." Finally, and to a much lesser extent, some survivors show a genuine willingness to forgive those who harmed them. This is a theme discussed by most of the survivors, but for many it is clear that although they recognise the societal value of forgiveness, they are personally not ready. However, in a few rare cases, such as this one, a survivor shows a genuine willingness to forgive, not only through his words, but through his actions: "Honestly he [the perpetrator who killed his mother and two siblings] approached me; he was open when he talked about the genocide and told me how it was planned, how it was done and his participation. And he admitted what he did. He also begged for forgiveness. I think he is a changed person to the extent in our daily lives we meet and greet. I even invited him to my wedding, but he missed it due to sickness."

\section{Summary \& Future Directions:}

Post-traumatic growth involves the study of positive personality change in the aftermath of highly challenging and often traumatic life circumstances (Jayawickreme \& Blackie, 2014). We 
have critically considered a model proposed by Staudinger \& Kunzmann (2005) that distinguishes between two types of personality change - adjustment and growth - to determine whether post-traumatic growth might be better conceived as the development of character traits and virtues indicative of human flourishing. In our sample of 32 oral testimonies from survivors of the 1994 genocide in Rwanda, we have found some evidence supporting this model insofar as some positive outcomes reported by survivors appear to promote adaptation to post-genocide Rwanda (e.g. acceptance, hope, and duty), whereas other outcomes are arguably expressive of personal human flourishing (e.g. wisdom, empathy and forgiveness).

Still, our data cannot demonstrate conclusively that adjustment and growth are mutually distinctive categories. In fact, depending on the person and the context, post-traumatic growth may be congruent with, and supportive of, an individual's process of adjustment to a posttrauma reality. We would argue that this is a likely outcome in our data. For example, a survivor who feels a greater sense of empathy towards her fellow survivors might invest in these relationships, and develop a social support network that eventually enables her to accept and adjust to her post-genocide reality. We would therefore suggest that the adjustment-growth distinction made by Tedeschi \& Calhoun (2004) might be too sharply drawn and exclusively applicable to only a small number of cases. In any event, there may be a need for future research to move beyond this distinction towards a more detailed narrative analysis of individual cases that explores the interaction between the two psychological processes. In this respect, our chapter takes an initial step in this direction by demonstrating that adjustment and post-traumatic growth are identifiable features of Rwandan post-genocide society. It also points to interesting directions for future research on the implications of such human tragedies for the formation of moral virtue and character. 


\section{$\underline{\text { References: }}$}

Ano, G. G., \& Vasconcelles, E. B. (2005). Religious coping and psychological adjustment to stress: A meta-analysis. Journal of Clinical Psychology, 61(61), 461-480. http://doi.org/10.1002/jclp.20049

Arnold, J. (2011). A Psychological Investigation of Individual and Social Transformations in Post-Genocide Rwanda. In R. Provost \& Akhavan (Eds.), Confronting Genocide (pp. 305317). Springer Netherlands.

Burns, S. (2004). Forgiveness in challenging circumstances. In F. Watts \& L. Gulliford (Eds.), Forgiveness in context: Theology and psychology in creative dialogue (pp. 144-159). London: T\&T Clark International.

Caspi, A., \& Roberts, B. W. (2001). Personality Development Across the Life Course:The Argument for Change and Continuity. Psychological Inquiry, 12(2), 49-66. http://doi.org/10.1207/S15327965PLI1202_01

Clark. (2010). The Gacaca Courts, Post-Genocide Justice and Reconciliation in Rwanda. Cambridge University Press.

Ford, J. D., Tennen, H., \& Albert, D. (2008). A Contrarian View of Growth Following Adversity. In S. Joseph \& P. A. Linley (Eds.), Trauma, Recovery, and Growth: Positive Psychological Perspectives on Posttraumatic Stress (pp. 295-324). John Wiley \& Sons, Inc.

Funder, D. C. (2001). Personality. Annual Review of Psychology, 52(1), 197-221. http://doi.org/10.1146/annurev.psych.52.1.197

Helson, R., Jones, C., \& Kwan, V. Y. S. (2002). Personality change over 40 years of adulthood: Hierarchical linear modeling analyses of two longitudinal samples. Journal of Personality and Social Psychology, 83(3), 752-766. http://doi.org/10.1037/0022-3514.83.3.752

Hoerger, M., Chapman, B. P., Prigerson, H. G., Fagerlin, A., Mohile, S. G., Epstein, R. M., ... Duberstein, P. R. (2014). Personality Change Pre- to Post- Loss in Spousal Caregivers of 
Patients With Terminal Lung Cancer. Social Psychological and Personality Science, 5(6), 722 729. http://doi.org/10.1177/1948550614524448

Janoff-Bulman, R. (2010). Shattered Assumptions. New York: Simon and Schuster. Jayawickreme, E., \& Blackie, L. E. R. (2014). Post-traumatic Growth as Positive Personality Change: Evidence, Controversies and Future Directions. European Journal of Personality, 28(4), 312-331. http://doi.org/10.1002/per.1963

Jayawickreme, N., Jayawickreme, E., Goonasekera, M. A., \& Foa, E. B. (2009). Distress, wellbeing and war: qualitative analyses of civilian interviews from north eastern Sri Lanka: Intervention, 7(3), 204-222. http://doi.org/10.1097/WTF.0b013e328334636f

Joseph, S., \& Linley, P. A. (2005). Positive Adjustment to Threatening Events: An Organismic Valuing Theory of Growth Through Adversity. Review of General Psychology, 9(3), 262-280. http://doi.org/10.1037/1089-2680.9.3.262

Kroo, A., \& Nagy, H. (2011). Posttraumatic Growth Among Traumatized Somali Refugees in Hungary. Journal of Loss and Trauma, 16(5), 440-458. http://doi.org/10.1080/15325024.2011.575705

Kunzmann, U., \& Baltes, P. B. (2003). Wisdom-Related Knowledge: Affective, Motivational, and Interpersonal Correlates. Personality and Social Psychology Bulletin, 29(9), 1104-1119. http:/ / doi.org/10.1177/0146167203254506

Linley, P. A. (2003). Positive adaptation to trauma: Wisdom as both process and outcome. Journal of Traumatic Stress, 16(6), 601-610. http://doi.org/10.1023/B:JOTS.0000004086.64509.09

Linley, P. A., \& Joseph, S. (2004). Positive change following trauma and adversity: A review. Journal of Traumatic Stress, 17(1), 11-21. http://doi.org/10.1023/B:JOTS.0000014671.27856.7e

Löckenhoff, C. E., Terracciano, A., \& Costa Jr., P. T. (2009). Five-factor model personality traits and the retirement transition: Longitudinal and cross-sectional associations. Psychology and Aging, 24(3), 722-728. http://doi.org/10.1037/a0015121 
Lucas, R. E., \& Donnellan, M. B. (2011). Personality development across the life span: Longitudinal analyses with a national sample from Germany. Journal of Personality and Social Psychology, 101(4), 847-861. http://doi.org/10.1037/a0024298

Lurie-Beck, J. K., Liossis, P., \& Gow, K. (2008). Relationships between psychopathological and demographic variables and posttraumatic growth among Holocaust survivors. Traumatology, 14(3), 28-39. http://doi.org/10.1177/1534765608320338

Mroczek, D. K., \& Spiro, A. (2003). Modeling Intraindividual Change in Personality Traits: Findings From the Normative Aging Study. The Journals of Gerontology Series B: Psychological Sciences and Social Sciences, 58(3), 153-165. http://doi.org/10.1093/geronb/58.3.P153

Park, N., \& Peterson, C. (2009). Character Strengths: Research and Practice. Journal of College and Character, 10(4), 1-10. http://doi.org/10.2202/1940-1639.1042

Peterson, C., Park, N., Pole, N., D’Andrea, W., \& Seligman, M. E. P. (2008). Strengths of character and posttraumatic growth. Journal of Traumatic Stress, 21(2), 214-217. http://doi.org/10.1002/jts.20332

Powell, S., Rosner, R., Butollo, W., Tedeschi, R. G., \& Calhoun, L. G. (2003). Posttraumatic growth after war: A study with former refugees and displaced people in Sarajevo. Journal of Clinical Psychology, 59(1), 71-83. http://doi.org/10.1002/jclp.10117

Roberts, B. W., Caspi, A., \& Moffitt, T. E. (2001). The kids are alright: Growth and stability in personality development from adolescence to adulthood. Journal of Personality and Social Psychology, 81(4), 670-683. http://doi.org/10.1037/0022-3514.81.4.670

Roberts, B. W., Caspi, A., \& Moffitt, T. E. (2003). Work experiences and personality development in young adulthood. Journal of Personality and Social Psychology, 84(3), 582-593. http:/ / doi.org/10.1037/0022-3514.84.3.582

Roberts, B. W., Helson, R., \& Klohnen, E. C. (2002). Personality Development and Growth in Women Across 30 Years: Three Perspectives. Journal of Personality, 70(1), 79-102. http://doi.org/10.1111/1467-6494.00179 
Roberts, B. W., \& Mroczek, D. (2008). Personality Trait Change in Adulthood. Current Directions in Psychological Science, 17(1), 31-35. http://doi.org/10.1111/j.1467-8721.2008.00543.x

Salo, J., Punamäki, R.-L., Qouta, S., \& Sarraj, E. E. (2008). Individual and Group Treatment and Self and Other Representations Predicting Posttraumatic Recovery Among Former Political Prisoners. Traumatology, 14(2), 45-61. http://doi.org/10.1177/1534765608319079

Seaton, C. L. (2009). Psychological Adjustment. In S. J. Lopez (Ed.), Encyclopedia of Positive Psychology (pp. 796-801). Wiley.

Seligman, M. E. P., \& Csikszentmihalyi, M. (2000). Positive psychology: An introduction. American Psychologist, 55(1), 5-14. http://doi.org/10.1037/0003-066X.55.1.5

Smith, J., \& Baltes, P. B. (1990). Wisdom-related knowledge: Age/cohort differences in response to life-planning problems. Developmental Psychology, 26(3), 494-505. http://doi.org/10.1037/0012-1649.26.3.494

Specht, J., Egloff, B., \& Schmukle, S. C. (2011). Stability and change of personality across the life course: The impact of age and major life events on mean-level and rank-order stability of the Big Five. Journal of Personality and Social Psychology, 101(4), 862-882. http://doi.org/10.1037/a0024950

Survivors Fund. (n.d.). Retrieved from http://survivors-fund.org.uk/resources/rwandanhistory/statistics/

Staub, E., \& Vollhardt, J. (2008). Altruism Born of Suffering: The Roots of Caring and Helping After Victimization and Other Trauma. American Journal of Orthopsychiatry, 78(3), 267-280. http://doi.org/10.1037/a0014223

Staudinger, U. M. (1999). Older and Wiser? Integrating Results on the Relationship between Age and Wisdom-related Performance. International Journal of Behavioral Development, 23(3), 641664. 
Staudinger, U. M., \& Kunzmann, U. (2005). Positive Adult Personality Development. European Psychologist, 10(4), 320-329. http://doi.org/10.1027/1016-9040.10.4.320

Staudinger, U. M., Smith, J., \& Baltes, P. B. (1992). Wisdom-related knowledge in a life review task: Age differences and the role of professional specialization. Psychology and Aging, 7(2), 271-281. http://doi.org/10.1037/0882-7974.7.2.271

Taylor, S. E., \& Armor, D. A. (1996). Positive Illusions and Coping with Adversity. Journal of Personality, 64(4), 873-898. http://doi.org/10.1111/j.1467-6494.1996.tb00947.x

Tedeschi, R. G., \& Calhoun, L. G. (1996). The Posttraumatic Growth Inventory: Measuring the positive legacy of trauma. Journal of Traumatic Stress, 9(3), 455-471. http://doi.org/10.1007/BF02103658

Tedeschi, R. G., \& Calhoun, L. G. (2004). Posttraumatic Growth: Conceptual Foundations and Empirical Evidence. Psychological Inquiry, 15(1), 1-18. http://doi.org/10.1207/s15327965pli1501_01

Tedeschi, R. G., Park, C. L., \& Calhoun, L. G. (1998). Posttraumatic Growth: Conceptual Issues. In R. G. Tedeschi, C. L. Park, \& L. G. Calhoun (Eds.), Posttraumatic Growth: Positive Changes in the Aftermath of Crisis (pp. 1-22). Mahwah, NJ: Lawrence Erlbaum.

Tomich, P. L., \& Helgeson, V. S. (2004). Is Finding Something Good in the Bad Always Good? Benefit Finding Among Women With Breast Cancer. Health Psychology, 23(1), 16-23. http://doi.org/10.1037/0278-6133.23.1.16

Williamson, C. (2014). Towards a theory of collective posttraumatic growth in Rwanda: The pursuit of agency and communion. Traumatology: An International Journal, 20(2), 91-102. http://doi.org/10.1037/h0099393

Williamson, C. (2016). Genocide, masculinity and posttraumatic growth in Rwanda: reconstructing male identity through ndi umunyarwanda. Journal of Genocide Research, 18(1), 41-59. http://doi.org/10.1080/14623528.2016.1120463 